\title{
Climate Shocks and (very) Long-Run Productivity*
}

\author{
Carl-Johan Dalgaard ${ }^{\dagger} \quad$ Casper Worm Hansen ${ }^{\ddagger} \quad$ Nicolai Kaarsen ${ }^{\S}$
}

September, 2015

\begin{abstract}
The present study examines the link between temperature and long-run productivity for a balanced panel of 21 countries, covering the period 1000-1800 CE. Collectively the countries examined accounted for about $2 / 3$ of the global population by 1700 . Each epoch in the analysis is a century long, which thus allows time for human adaptation after a temperature shock has occurred. Our principal finding is that lower temperatures worked to reduce productivity growth during the period in focus, consistent with contributions to the literature in economic history that argue the Little Ice Age was as a contractionary shock.
\end{abstract}

JEL Classification codes: O47; O57; N10

Keywords: Climate shocks; Little Ice Age; Productivity growth

\footnotetext{
${ }^{*}$ We would like to thank Philipp Ager, Henrik Hansen, Peter Sandholt Jensen, Lars Lønstrup, Pablo Selaya, Battista Severgnini and Workshop participants at the University of Copenhagen and the University of Southern Denmark for useful comments and suggestions.

${ }^{\dagger}$ Department of Economics, University of Copenhagen and CEPR. carl.johan.dalgaard@econ.ku.dk

${ }^{\ddagger}$ Department of Economics, University of Copenhagen. Casper.worm.hansen@econ.ku.dk

${ }^{\S}$ Kraka. Contact: nk@kraka.org.
} 


\section{Introduction}

As temperatures have risen during the 20th century, and climate projections suggest additional warming of between 1.1 and 6.4 degrees Celsius during the 21st century (NRC, 2010), understanding the potential economic consequences of climate change on human societies has become a central issue among policy makers as well as academics. ${ }^{1}$

The present study provides new evidence on the impact from long lasting climate shocks on productivity by examining the link between temperature and productivity growth across European and Asian countries during most of the second millennium - $1000 \mathrm{CE}$ to $1800 \mathrm{CE}$ - using panel data regression analysis. Our principal finding is that declining temperature led to declining productivity growth during the period in question, which is broadly consistent with contributions to the literature in economic history, discussed below, that argues the shift from the so-called "Medieval Warm period" (ca. 950-1250 CE) to "the Little Ice Age" (ca. 1550-1850) was a contractionary shock. ${ }^{2}$

Our empirical strategy is similar in spirit to that of Dell et al. (2012), who examine the link between temperature and GDP per capita during the post World War II period by employing panel data estimation. The objective is thus to obtain the best possible estimate of the reduced-form impact from temperature on labor productivity. In contrast to Dell et al. (2012), however, we examine the impact from long-lasting temperature deviations from (very) long run averages; each of the time epochs in our panel is 100 years long.

Focusing on (very) long-run developments provide, we believe, useful complementary information about the link between climate shocks and productivity. In the existing literature a number of channels, which potentially link climate to growth, has been proposed: The list includes the potential impact on agricultural output (e.g., Greenstone and Deschênes, 2007); on health and labor supply (e.g., McMichael et al., 2006; Heal and Park, 2014; Barreca et al, 2015); on anti-social behavior (e.g., Oster, 2004; Anderson et al. 2015) and on all-out conflict (Miguel et al, 2004; Harari and La Ferrara, 2013; Jia, 2014; Iyigun et., 2015). As it seems likely that the (relative) impact of these (and other potential) channels may vary depending on the time horizon in focus, the net impact on productivity growth may also vary depending on the observation window. For instance, whereas a shock of a one year duration may have devastating effects on the harvest, more persistent changes in climate may encourage human

\footnotetext{
${ }^{1} \mathrm{~A}$ review of the recent literature on the link between climate change and productivity growth is found in Dell et al. (2014).

${ }^{2}$ There has been some debate about which exact period should be labeled "the Little Ice Age" (and whether it occurred at all; cf. below). Here we use the dating proposed by NASA. (cf. http://earthobservatory.nasa.gov/ Glossary/?xref=Little\%20Ice\%20Age).
} 
adaptation, which counteracts the initial shock. ${ }^{3}$ If, on the other hand, human adaptation is ineffective and if the negative impact of climate change accumulates over time, the consequences of long term climate change could be more severe than those of year-to-year shocks. In the end, this issue can only be resolved empirically.

A challenge for the present study is how to measure productivity growth during the period in focus. Prior to the demographic transition, however, changes in productivity would work to change net fertility. In short, periods of plenty would tend to instigate population growth and thus greater population density (e.g., Ashraf and Galor, 2011; Dalgaard and Strulik, 2015). Hence, in the analysis below we rely on population size as a marker for productivity. Along with reconstructed temperature data described below, we regress the former on the latter to tease out information about the long-run impact from temperature on productivity. It stands to reason that this data is noisy. However, under standard assumptions both sources of measurement error work to mute the link between temperature and productivity; either by inflating standard errors (dependent variable measured with error), or by instigating an attenuation bias (independent variable measured with error). If anything, then, our estimates below should be viewed as a lower bound on the very long-run reduced-form effect of temperature on growth. ${ }^{4}$

In the analysis below we expose our baseline results to a battery of robustness checks. Since we are able to control for country-specific effects, as well as region-specific time fixed effects, the main threat to identification is the potential for time-varying omitted variable bias. In this regard the major issue is whether the estimated impact from temperature on growth could be convoluting the influence from geographically related secular changes in the economies in focus that just happen to be correlated with temperature. For example, the post-Columbian period witnesses the emergence of trade across the Atlantic, which likely influences economic development in fundamental ways (Acemoglu et al., 2005). If temperature changes are correlated with the extent of coastal orientation, our reduced form estimates will be biased, since the processes unleashed by the emergence of transatlantic trade would have preciously little to do with temperature per se. Hence, in the analysis below we carefully try to "filter out" potentially geographically related time-varying information of this kind. Another worry could be that it is the variance of temperature (over a century), and not the temperature average,

\footnotetext{
${ }^{3}$ For example, De Vries (1980) notes that Buckwheat, which requires a relatively short growing season, seems to have become more important in the Netherlands during the Little Ice Age, and declined in importance in the 18th century. See also Olmstead and Rhode (2011) on the diffusion of wheat to colder and more arid areas of the US from the 19th century onwards.

${ }^{4}$ Of course, even if data on GDP growth were available, such data would likely also be noisy indicators of economic activity. That at least seems to be the case for the post 1950 period; see, e.g., Johnson et al. (2013).
} 
that matters to growth. These, and other, issues are confronted in the empirical analysis below. In the end our baseline results appear to be quite robust: during the period $1000 \mathrm{CE}-1800 \mathrm{CE}$, and in the regions for which we have data, the impact from temperature and productivity growth is positive. An increase in mean temperature by one degree Celsius instigates an increase in the annual average growth rate in productivity by 0.05 percentage points.

The present study is related to several previous contributions. First and foremost the study by Dell et al. (2012) find, for the post WWII period, that positive temperature shocks lower productivity growth in the poorest countries. In the present study, which focuses exclusively on poor and highly agriculturally dependent nations over a much longer period of time we find the opposite. Another related study is that by Waldinger (2014). Waldinger investigates the reduced form link between temperature and city-level population across Europe; the panel covers the period 1500-1750. The main result is that increasing temperature served to increase urban population size. If urban population size is a sensible proxy for productivity this result is consistent with our country-level results, which pertain to an expanded window of observation. Also related is an earlier time series study by Galloway (1986), which focuses on the link between population growth and climate, using a solar activity index as a stand-in for temperature in Western Europe and China, respectively. Consistent with our results Galloway finds a positive link between solar activity and population growth in both Western Europe and China over the period from $400 \mathrm{BCE}$ to $1800 \mathrm{CE}$. In contrast to Galloway, we are able to invoke country-level information on both population growth and temperature. ${ }^{5}$

The present study is also related to a literature within economic history, which has debated the impact of climatic conditions on development during the second millennium CE. As discussed in the next section, arguments have been made that the Little Ice Age was everything from a negative destabilizing shock to (eventually) a benefit, due to technological advances within agriculture prompted by adversities faced by European farmers due to the colder weather.

We proceed as follows. In the next section we discuss the work of (economic) historians with bearing on the topic at hand. Subsequently we develop the empirical strategy in Section 3. Section 4 describes our data, and Section 5 presents our results. Finally, Section 6 concludes.

\footnotetext{
${ }^{5}$ Of course, there is a number of studies which has regressed temperature on economic activity in a cross section of countries, or a cross section of regions. See Dell et al. (2014) for an overview.
} 


\section{The Little Ice Age and Development: Historical Perspectives}

The current orthodoxy within climate research is to view the period $1000 \mathrm{CE}$ until $1800 \mathrm{CE}$ as encompassing two broad regimes: The Medieval Warm period (circa 1000-1200) and the so-called Little Ice Age. The timing of the Little Ice Age is a contested issue, and so is its global reach and detailed temporal characteristics. Mann (2002, p. 506) summarizes the evidence in the following way:

While the 17th century appears to represent the timing of peak cooling in Europe, the 19th century was more clearly the period of peak cold in North America...Even farther a field in eastern China, there is less evidence of any distinct cold period during the latter centuries of the millennium, with temperatures rather relatively uniformly depressed from about AD 1100-1800

Accordingly, while most climatologists appear to subscribe to the view that temperatures were depressed during the second millennium CE, until somewhere in the 19th century, the consensus also seems to be that the most dramatic cold spells were not necessarily synchronous across Eurasia. Similarly, the causes of the cold spells is in debate; viable hypothesis include reduced solar activity levels and an increasing frequency of volcanic eruptions. ${ }^{6}$

In terms of the consequences of the Little Ice Age to human societies, Lamb (1965) were among the first to argue that the Little Ice Age was a prime mover in leading to the collapse of the Norse settlements in Southern Greenland. A similar assessment is found in the more recent work of Diamond (2005). The argument is that an increasingly colder environment led to the loss of livestock and to isolation from the European continent, which previously had been an important trading partner. ${ }^{7}$ Since the Norse population appears to have been unwilling to learn from Greenland's indigenous population on how to survive in the arctic environment their fate was by all accounts sealed.

The European continent also seems to have felt the consequences of changing climatic conditions. Particular cold periods were experienced during the second half of the 16th century, and perhaps especially during the 17th century as observed by Mann (2002). Over the years a number of contributions have offered hypotheses about the likely impact from these shocks on the economy.

In his landmark contribution The Mediterranean and the Mediterranean World in the Age of Philip II, Fernand Braudel (1966) alluded to the possibility that the demise of the Mediterranean as the center

\footnotetext{
${ }^{6}$ It should be noted that the notion of "A Little Ice Age" itself also has been challenged. For example, an entire issue of the journal Climate Change was in 2001 dedicated to the question of whether the term is warranted or not. For a recent installment to this debate, see Kelly and O'Grada (2014) who dismisses the notion of a Little Ice Age altogether.

${ }^{7}$ Fagan (2000, p. 63) cites a letter by Alexander VI from 1492, where the Pope remarks that no ship is believed to have been ashore in Greenland for 80 years due to the freezing of the waters.
} 
of economic power during the 16th century could have been related to climatic factors:

If it is agreed ... that in about 1600 the weather did indeed become colder and wetter, it would also explain the frosts which were so disastrous for the olive trees and the frequent floodings...not to mention the spread of marshland and consequently of malaria, creating overall conditions of increased difficulty for human life...The roots of the social crisis caused by the food shortage that dominated the end of the century may have lain in an alteration, even a very slight one, in the atmospheric conditions.

- Braudel (1966, p. 270)

Arguably, however, conditions were not necessarily much better outside the Mediterranean basin. Fagan (2000), who primarily focuses on developments in Northern Europe, evaluates conditions during the second half of the 16th century as follows (p. 91):

As climatic conditions deteriorated, a lethal mix of misfortunes decended on a growing European population. Crops failed and cattle perished by diseases caused by abnormal weather. Famine followed famine bringing epidemics in their train, bread riots and general disorder brought fear and distrust.

The envisioned link between climate and social unrest during the end of the 16th century seems to resonate with more recent empirical work. Oster (2004) detects an increasing frequency of witchcraft trials during periods of climatic stress between the 16th and 17th century, which also fits with analyses based on achival records from the witch-trails. As Behringer (1995) observes (p. 4):

...during the major witchcraft persecutions of Central Europe in the sixteenth century, accusation of weather-magic (Wettermacheri) recurred with striking frequency.

On the theme of scape-goating, Anderson et al. (2015) documents that expulsions of Jews from European cities were significantly more common in years involving colder temperatures, during the period $1100 \mathrm{CE}-1800 \mathrm{CE}$. A similar link between poor weather conditions and conflict is found in China over the period 1470 to 1900 (Jia, 2014). On an even grander scale, Parker (2008) hypothesizes that climatic conditions were a contributing factor to the extraordinary high frequency of state collapse across Eurasia (and beyond) during the 17th century; what historians sometimes refer to as "the General Crisis" (See also De Vries, 2009). 
At the same time it should be pointed out that some economic historians do not share the view that climatic conditions influenced agriculture and mortality during the period 1500-1800. Fogel (1992), for instance, argues that the famines that England experienced between $1500 \mathrm{CE}$ and 1800 CE were all man made and not due to climate shocks. Appelby (1980) similarly argues that the main epidemics between 1300 and 1800 (such as the Plague) were unlikely to have been facilitated by climatic conditions. ${ }^{8}$ Finally, it has also been suggested that the climate induced adversities, faced by European farmers during the Little Ice Age, may ultimately have helped instigate an agricultural revolution across Europe, albeit perhaps not in equal measure everywhere (Fagan, 2000, Ch. 6).

In the end, therefore, it would seem premature to argue that a consensus, on the net impact of climate shocks on economic activity during the second millennium, has been reached within the historical literature. While some argue in favor of a destabilizing impact from declining temperatures, due to famine and disease, others argue that the impact was second order or even positive in the long run due to technological change prompted by the Little Ice Age. In the remaining we contribute to this debate by providing econometric evidence on the temperature/productivity nexus from the Medieval Warm period until the end of the Little Ice Age.

\section{Empirical Strategy}

The analysis conducted by Dell et al. (2012) starts from a growth accounting equation and proceeds by making assumptions about how temperature may impact on productivity; both in terms of levels and growth. In the present study we are faced by the challenge that no reliable data on GDP exist for the bulk of the time period studied. Hence, in order to make progress, we need some additional structure so as to enable the derivation of a viable regression model in observables that allows for a structural interpretation of the results.

In the analysis below we rely on the standard Malthusian macro model along the lines of Ashraf and Galor (2011). In their overlapping generations model, population is endogenous and determined by income per capita; higher living standards increases net fertility. If income per capita increases due to, for instance, a positive technology shock, population subsequently grows. When population increases, however, production per capita drops because of decreasing returns to labor. Eventually, when income has declined to the level of subsistence, population growth comes to a halt and the economy is in a steady state.

\footnotetext{
${ }^{8}$ See Schmida et al (2015) for a contrarian view.
} 
In our baseline analysis, we abstract from transitional dynamics and assume the economy adjusts to its steady state within a period, implying that income per worker is "always" (i.e., at the time of empirical observation) at the subsistence level. This is not necessarily a bad assumption in the present case since each time period in our data set is 100 years long. ${ }^{9}$ Nevertheless, we relax this assumption in a robustness check.

Hence, production per worker in country $i$ at time $t$ is assumed to be given by:

$$
\frac{Y_{i t}}{L_{i t}}=\mu_{i t}
$$

where $Y_{i t}$ is production, $L_{i t}$ is the labor force (i.e., the adult population), and $\mu_{i t}$ is the subsistence level of income, which implicitly convolutes preference parameters, the unit cost of children, and influences from the (child) mortality environment.

Total production at time $t$ occurs according to the following Cobb-Douglas production function:

$$
Y_{i t}=A_{i t} L_{i t}^{\alpha} X^{1-\alpha}
$$

where $A_{i t}$ captures the productivity level in the economy, and $X$ is land employed in production. The level of productivity is to be interpreted broadly so as to include both technology and elements such as the suitability of land for agriculture.

Combining equations (1) and (2) one obtains:

$$
L_{i t}=\left[\mu_{i t} A_{i t}\right]^{1 /(1-\alpha)} X
$$

Accordingly, this equation is assumed to hold at all points in time, $t$.

Moving beyond the standard framework, we assume that $\mu$ depends on temperature, $T_{i t}$ :

$$
\mu_{i t}=\bar{\mu}_{i} e^{\sigma T_{i t}}
$$

where $\sigma$ represents the reduced-form impact from temperature on subsistence income, implicitly capturing an impact of temperature on net fertility, mediated by disease or perhaps conflict. ${ }^{10}$ Moreover,

\footnotetext{
${ }^{9}$ Moreover, focusing on steady state behavior in the context of empirical testing is a quite common approach in the literature; see, for instance, Acemoglu and Johnson (2007) and Ashraf and Galor (2011).

${ }^{10}$ If only offspring that reach adulthood are costly to the household, child mortality will not affect net fertility when preferences are Cobb-Douglas (e.g., Galor, 2011, Ch. 4). However, if there are costs of child bearing, regardless of whether the child survives long enough to reach reproductive age, greater child mortality will work to lower fertility (see Doepke, 2005).
} 
and following Dell et al. (2012), we assume that productivity is influenced by temperature:

$$
A_{i t}=\left(1+g_{i}+\gamma T_{i t}\right)^{t} e^{\beta T_{i t}} A_{i 0}
$$

Hence, we allow each country to - potentially - follow different productivity paths in terms of both the rate of the trend growth rate and the level of the trajectory. ${ }^{11}$ The notion is that climatic shifts impacts directly on agricultural productivity, and perhaps indirectly on $A$ via the incentive to innovate.

Taking logs and first differences in equation (3) and using equations (5) and (4) yields

$$
l_{i t} \approx \frac{1}{1-\alpha} g_{i}+\frac{\gamma+\beta+\sigma}{1-\alpha} T_{i t}-\frac{\beta+\sigma}{1-\alpha} T_{i t-1}
$$

where $l_{i t} \equiv \ln L_{i t}-\ln L_{i t-1}$ is population growth in country $i$ during period $t$ (between time $t-1$ and $t$ ), and $T_{i t}$ is the mean temperature during period $t .{ }^{12}$ Equation (6) can be formulated as a standard fixed-effects regression model:

$$
l_{i t}=\theta_{i}+\theta_{r t}+\pi_{1} T_{i t}+\pi_{2} T_{i t-1}+\varepsilon_{i t},
$$

where $\theta_{i}$ is a country fixed effect, $\theta_{r t}$ reflects region-by-time fixed effects and $\varepsilon_{i \tau}$ captures noise and omitted country-specific time-varying determinants of population growth. This is our baseline specification, and the coefficients $\pi_{1} \equiv(\gamma+\beta+\sigma) /(1-\alpha)$ and $\pi_{2} \equiv-(\beta+\sigma) /(1-\alpha)$ are the parameters of interest.

Accordingly, when studying the impact from temperature on the growth process, we allow the average productivity growth rate to vary from country to country through the fixed effect $\theta_{i}$. In addition, we allow the average productivity growth rate to differ between regions (Europe, Asia) in a time varying fashion through $\theta_{r \tau}$; being relatively faster in Asia until $1500 \mathrm{CE}$ and slower thereafter, for instance.

When estimating equation (7) it is clear that reverse causality is not going to be a concern. Nor is it a concern that a host of time-varying structural characteristics that may be influenced by the evolution of temperature is omitted (e.g., conflict). Rather, the obtained estimates for $\pi_{1}$ and $\pi_{2}$ are to be interpreted as the reduced-form effect of temperature on population growth and thus

\footnotetext{
${ }^{11}$ Technically speaking, Dell et al. (2012) allow the level effect $\left(e^{\beta T_{i t}}\right)$ to enter the production function directly and separately specify a link between temperature and the growth rate of $A$. When the production function is Cobb-Douglas (as it is in Dell et al., 2012 and in the present context), the two formulations are isomorphic.

${ }^{12}$ Along the way we invoke the approximation that $\ln (1+x) \approx x$.
} 
productivity growth, mediated by such factors. However, there are four legitimate concerns that need to be confronted.

First, periods of changing average temperatures could also be periods of changing climatic variability. If so, and provided temperature variability matters to population growth in itself, our baseline estimates will be biased. ${ }^{13}$ To deal with this issue, we examine the robustness of our baseline findings to the simultaneous inclusion of controls for temperature variation.

Second, nonlinearities of temperature could potentially be important. That is, perhaps small changes in average temperature are significantly less important than larger shocks? To deal with this issue (misspecification error) we also experiment with versions of (8) that allow temperature to enter in a non-linear fashion.

Third, one might worry that temperature could be spuriously correlated with geographic characteristics that feature a time-varying impact on productivity growth. For example, the period in focus witnessed a reversal in fortune with respect to absolute latitude; in $1500 \mathrm{CE}$ the most densely settled and urbanized regions were found close to the equator, in contrast to the current state of affairs. If temperature changes were more marked during the period in (say) places closer to the equator, our estimates for the impact of temperature on population growth could be biased. ${ }^{14}$ To deal with this concern we also control for a range of country-specific geographic characteristics, $\mathbf{Z}_{i}^{\prime}$, interacted with time-period fixed effects, $\sum I_{t}^{j}$. In these robustness checks, we estimate the following model:

$$
l_{i t}=\theta_{i}+\theta_{r \tau}+\pi_{1} T_{i t}+\pi_{2} T_{i t-1}+\sum_{j=1100}^{1800} \mathbf{Z}_{i}^{\prime} I_{t}^{j} \Pi+u_{i t}
$$

Fourth, one may be concerned with the fact that we do not allow for convergence in our baseline specification, that is, perhaps the steady-state assumption is inappropriate? To deal with this issue, the appendix shows that allowing for convergence motivates the following empirical specification:

$$
l_{i t}=\theta_{i}+\theta_{r t}+\eta l_{i t-1}+\pi_{1} T_{i t}+\pi_{2} T_{i t-1}+v_{i t},
$$

where $l_{i t-1}$ is the lagged population growth rate. As is well known, standard OLS estimates of equation (9) are biased (Nickell, 1981). Hence, this specification is somewhat more complicated to estimate than equations (7) and (8). As a first approach, in dealing with this matter, we refer to the

\footnotetext{
${ }^{13}$ Fagan (2000), for example, argues strongly that temperature variability, and not the level of temperature, was key during the Little Ice Age.

${ }^{14}$ For former colonies this reversal may be explained by institutional transplantation (Acemoglu et al., 2002). But the reversal turns out to hold true for countries that were never colonies as well (Ashraf and Galor, 2011). See Dalgaard and Strulik (2014) for a possible explanation and an overview of alternative theories that have been proposed.
} 
argument that fixed effects estimation (without the lagged dependent variable) and lagged dependent variable estimation (without fixed effects) are bounding the causal effect (see, e.g., Angrist and Pischke, 2009). As an alternative to this strategy, one could invoke a GMM approach, such as the Arellano-Bond estimator (Arellano and Bond, 1991). But in the present context, where we are confined to a relatively "small $N$ " sample, this approach, which relies on assymptotics in the cross-section dimension, may not be optimal. Instead we therefore utilize the bias-corrected least squares dummy variables estimator (Kivert, 1995; 1999; Bruno, 2005).

As mentioned, the parameters of interest are (in all settings): $\pi_{1}$ and $\pi_{2}$. The parameter $\pi_{2}=$ $-(\beta+\sigma) /(1-\alpha)$ reflects the level effect which works through either productivity $(\beta)$ or subsistence consumption $(\mu)$. As $\pi_{1}=\gamma /(1-\alpha)+\pi_{2}$, the growth effect $(\gamma)$ can be obtained by subtracting the estimate of $\pi_{1}$ from the estimate of $\pi_{2}$. Notice, however, we cannot disentangle the levels influence which runs through productivity from that which runs through subsistence consumption. Since temperature may influence productivity and mortality in opposite directions, a net impact of $\pi_{2} \approx 0$ does not necessarily imply that there are no level effects on either one of these factors from temperature. While this is a limitation of the present approach, our estimates for $\pi_{2}$ does provide a rough guide to the plausible impact of temperature on the level of productivity if one is willing (guided by theory) to invoke priors on the influence from temperature on net fertility .

\section{Data}

The outcome variable is the centennial population growth rate for the period 1100-1900 CE, which has been constructed using population data from McEvedy and Jones (1978). This is the standard source of historical population data typically used in the literature. ${ }^{15}$ In principle, the McEvedy and Jones dataset spans the entire globe, however, for most countries data availability is very limited during the period 1000-1500 CE. As a result, our final dataset is a balanced panel of 21 countries, covering 18 European and three Asian countries. ${ }^{16}$ While the number of countries perhaps seems somewhat small, these 21 countries together hosted $2 / 3$ of the global population as of $1700 .^{17}$

\footnotetext{
${ }^{15}$ Studies invoking these data include Acemoglu et al. (2002), Ashraf and Galor (2011, 2013), Nunn (2008), Nunn and Qian (2011) among others.

${ }^{16}$ The countries in our panel are: Austria, Belgium, China, Cyprus, France, Germany, Hungary, India, Ireland, Iceland, Italy, Japan, Korea, Malta, Netherlands, Poland, Portugal, Romania, Spain, Switzerland and United Kingdom.

${ }^{17}$ Moreover, the lists of primary sources and bibliographies presented in McEvedy and Jones (1978) reveal that the population numbers for Europe and Asia are chiefly based on census data, military enumerations and archaeological evidence. Hence, data for this subsample of countries would appear somewhat more reliable than the data for Africa, the New World and Oceania, which appears a bit conjectual in nature, in regards to the first half of the second millenium C.E.
} 
Our main explanatory variable is the average temperature from $1000 \mathrm{CE}$ to $1800 \mathrm{CE}$. We construct this variable exploiting data from Mann et. al. (2009), who reconstruct gridded, yearly temperature from $500 \mathrm{CE}$ to $1850 \mathrm{CE}$. Their reconstruction relies on a number of proxy variables which are known to be correlated with temperature. For example, the width of treerings in radiocarbon-dated wood contain information about particularly warm or cold years. Likewise, the amount of pollen in lake sediments reveals whether the climate in a particular period was conducive to plant growth. The proxy data sets span various regions and various time periods.

They combine these data in a statistical framework to predict worldwide historical data of average yearly temperature from $500 \mathrm{CE}$ to $1995 \mathrm{CE}$ for each $5 \times 5^{\circ}$ grid cell. ${ }^{18}$ We aggregate this data to the country level the following way: We first produce centennial averages of temperature for each grid cell, which produces nine observations of average temperature for each grid cell—one for each of the centuries from the 11th to the 19th century. We then produce country means by averaging the area-weighted grid cells across the modern-day border of the country in question for each century.

To identify the effect of climate on development, we regress centennial changes in log population on the average temperature during the century controlling for country fixed-effects. For this strategy to succeed there needs to be a reasonable amount of within-country variation in both variables. Furthermore, since we include time-fixed effects, the variation should not be dominated by common shocks across all countries.

Figure 1, panel A investigates the within-country variation in population growth. For all countries except, Cyprus and Iceland, the average population increase is positive. Most countries have at least one or two centuries of negative population growth and many countries have at least one century of relatively fast population growth, where the log change exceeds 0.5. Compared to an average increase in $\log$ population across all countries is 0.19 this shows that there is reasonable within country variation in population growth.

Panel B of Figure 1 examines the variation in population growth from year to year. In all years, the change in log population differs by at least 0.4 going from the slowest to the fastest growing country. The Black Death clearly constitutes a negative common shock in the 14 th century. However, the severity of the shock varies considerably: The change in log population takes on a multitude of values in the interval from -0.6 to 0.25 .

Figure 2, panel A investigates the within-country variation in temperature. As is common in the

\footnotetext{
${ }^{18}$ The statistical procedure used is based on a so-called "regularized expectation maximization algorithm". First, the procedure relates observed temperature data series from 1850-1995 CE to proxy data from the same period. Then this fit is used to predict temperature data back in time using historical proxy data.
} 
climatology literature, temperature is measured in deviations from average temperature in the so-called baseline period from 1850-1995 (since all regressions contain country fixed effects, this normalization will not matter to the results). For most countries, the difference between the highest and the lowest temperature is around $0.5^{\circ}$. In comparison, the global temperature increased by about $0.6^{\circ}$ from 1951 to 2010 and ICCP (2014, p. 48) estimates that most of the effect is caused by human influences.

Panel B of Figure 2 examines the variation in temperature from year to year. The Medieval Warm Period mentioned above is visible in the data as slight increase in temperatures in most countries between $1000 \mathrm{CE}$ to $1100 \mathrm{CE}$. This period is followed by a decline in the 12th century and then a long period of stagnation. The emergence of the Little Ice Age is evident from the general drop in temperatures between the 15 th and 16th century. Notice, however, that the changes in temperature varies considerably during the Little Ice Age between countries: Some countries experience a slight increase during the 16 th century, others a decrease of $0.5^{\circ}$, with the remainder somewhere in between. The empirical analysis below draws on this sort of diversity in the severity of the Little Ice Age to identify the effect of temperature on development.

The drop in temperatures during the Little Ice Age is $0.24^{\circ}$ on average in Europe as well as in Asia. However, during the 16th century average temperature increases by $0.16^{\circ}$ in Asia but only by $0.04^{\circ}$ in Europe. It could be that these continental differences in the development in temperature are picking up secular trends related to region specific geographic features. To avoid the risk of biased estimates we therefore control for time dummies interacted with continent dummies in the regressions below, as explained above.

Finally. Table 1 reports summary statistics for the main variables in the regression analysis. We see that the standard deviation of temperature is 4.71. This number, however, mainly reflects crosssectional differences in temperature. As our identification comes from deviations in levels from the mean, we should evaluate the estimated model using the baseline statistics for 'temperature deviation', which has the mean -0.28 and a standard deviation of 0.28 . The remaining variables used in the regression analysis are explained as they are introduced.

[Table 1 about here] 
Figure 1: Centennial population growth rates by country

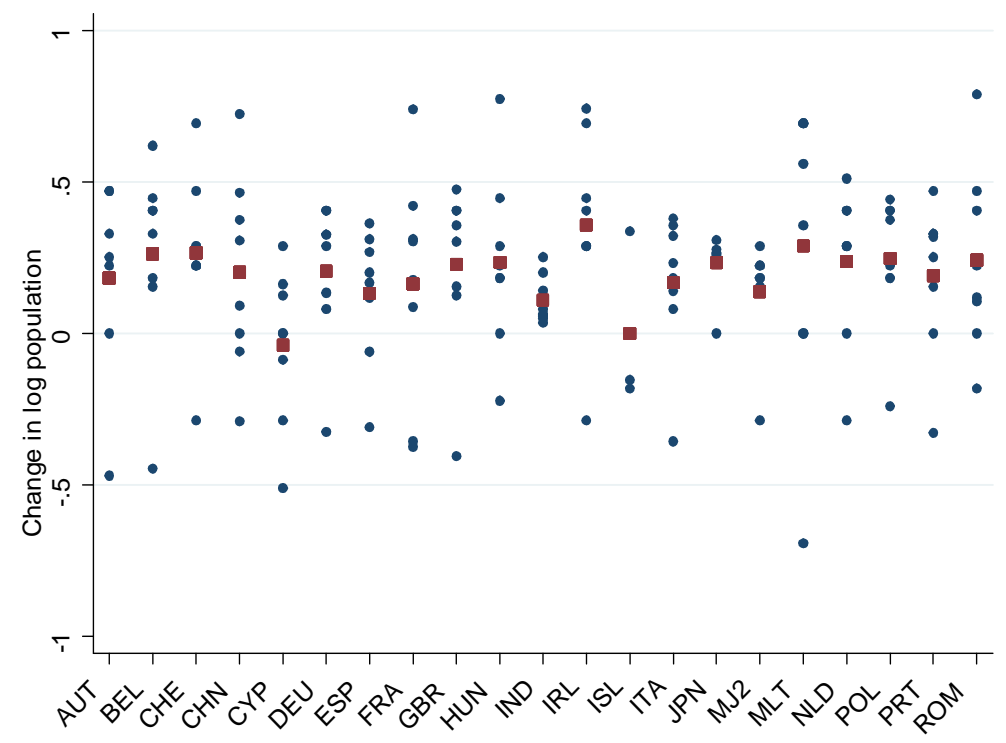

(A) Population growth by country.

Notes: Circles indicate mean change in log population for each of the 9 centuries from the 11th to the 19th. Squares indicate mean change in log population across all 9 centuries.

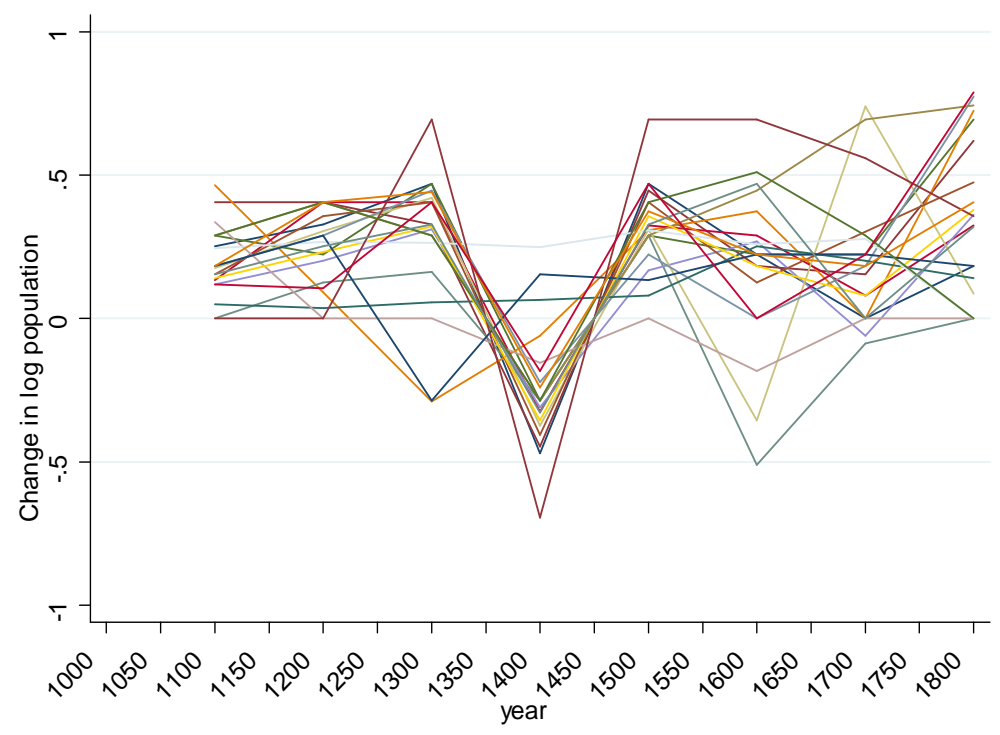

(B): Population growth across time and countries. 
Figure 2: Centennial temperature deviation from baseline by country

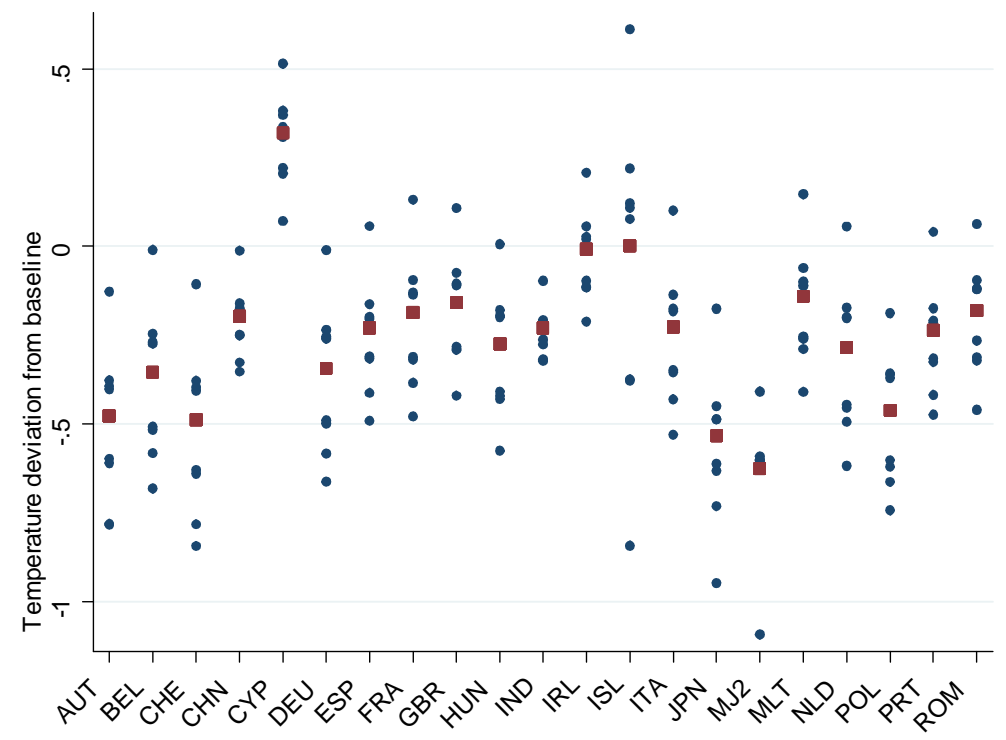

(A): Temperature deviation.

Notes: Temperature deviation in ${ }^{\circ} \mathrm{C}$ from average temperature from 1850-1995. Circles indicate average temperatures for each of the 9 centuries from the 11th to the 19th. Squares indicate mean temperatures across all 9 centuries.

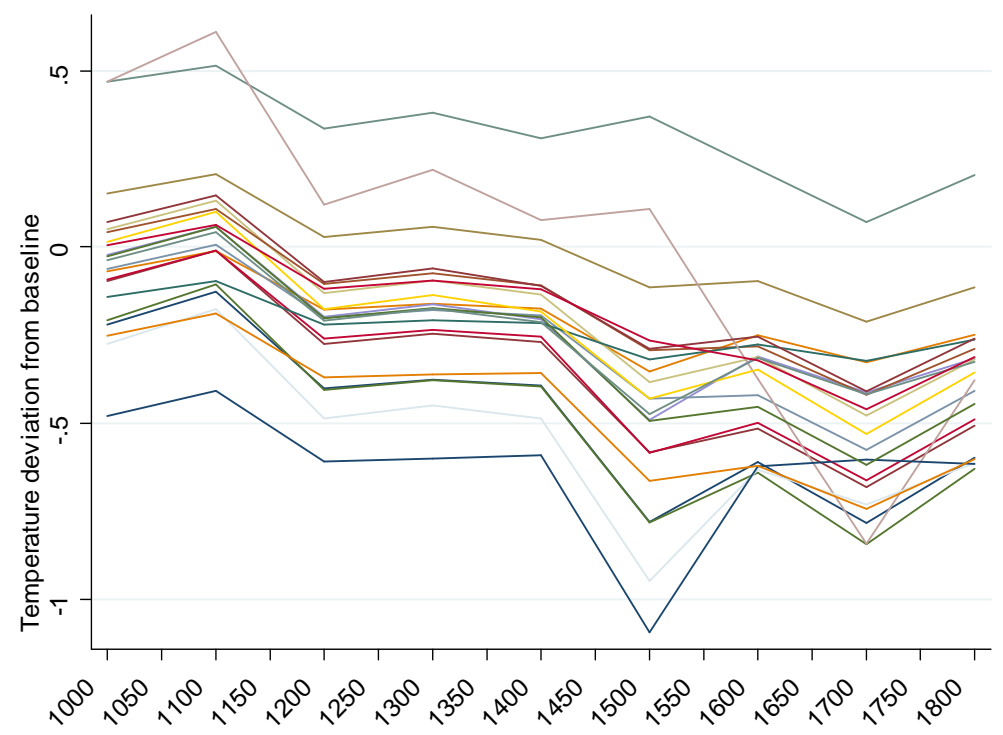

(B): Temperature deviation across time and counties 


\section{Empirical Analysis}

\subsection{Baseline Result}

Table 2 reports the results from the baseline specification (7). The first three columns include time fixed effects, while the remaining columns also include country fixed effects. The final column, which we consider as our preferred specification, additionally control for time-by-region fixed effects.

A number of features are notable in Table 2. First, the estimates reveal a statistically significant positive effect of temperature on population growth only when controlling for country fixed effects, suggesting that country heterogeneity in the growth rate of TFP - determined by unobserved country characteristics which are correlated with fixed climatic conditions -is important. In our preferred specification, reported in column 7 , the estimated coefficient $\hat{\pi}_{1}$ is equal to 0.26 (standard error $=$ 0.11). This implies that for a one degree lower temperature the population growth rate decreases by about 25 percentage point, which corresponds to an annual decrease in the population growth rate of 0.22 percentage points. Second, even though the estimated coefficient $\hat{\pi}_{2}$ is statistically significant at a 10 percent level in column 3, the effect of the lagged value of temperature on population growth is, in the remaining columns, not statistically significantly different from zero. For example, in our preferred specification, we see that $\hat{\pi}_{2}=-0.00$ (standard error $=0.23$ ). This finding is also confirmed in our subsequent robustness analysis.

Turning to economic significance, note from eqs. (6) and (7) that the coefficients of interest are $\pi_{1}=(\gamma+\beta+\sigma) /(1-\alpha)$ and $\pi_{2}=-(\gamma+\beta) /(1-\alpha)$. As $\hat{\pi}_{1}>0$ and $\hat{\pi}_{2}=0$, the implication is that $\hat{\sigma}+\hat{\beta}=0$, while $\hat{\gamma}>0$, which means that the considered climate changes seem to have had no reduced-form impact on the level of population, but rather influenced productivity growth. If we take the share of land as one-third, that is, $1-\alpha=1 / 3$, and therefore set the labor share to $\alpha=2 / 3$, this would imply that $\hat{\gamma}=0.17$ for $\hat{\pi}_{1}=0.26$. This estimate means that a one degree lower temperature is associated with an annual decrease in productivity growth of 0.15 percentage points. Figure 2 and the summary statistics, reported in Table 1, reveal that the mean temperature deviation is -0.28 degrees. Accordingly, on average the observed temperature shocks have served to lower long-run productivity by about 0.05 percentage points p.a.

[Table 2 about here] 


\subsection{Robustness}

This section establishes the robustness of our baseline findings of a positive significant estimate on temperature and an insignificant estimate on the lagged value of temperature with respect to the chosen specification.

\subsubsection{Allowing for Convergence}

Our first robustness check investigates the importance of the underlying assumption that countries are relatively close to their steady state when observed. As already mentioned, since each observation point is 100 years apart, the steady-state assumption may seem fairly reasonable. At the same time, little is known about the rate of convergence during Malthusian times for which reason the check seems warranted. ${ }^{19}$

Table 3 reports estimates controlling for lagged population growth to capture possible out-of steady state convergence, that is, mean-reverting dynamics in the outcome variable. The estimating equation is now eq. (9), which is more difficult to estimate due to the simultaneous presence of fixed effects and a lagged dependent variable. We deal with this in several ways.

First, we make use of a "bracketing property"; the "true" estimate (in the absence of other biases) is bounded by, on the one side, the estimate obtained with fixed effects and no lagged dependent variable, and, on the other side, the estimate obtained without fixed effects but allowing for the lagged dependent variables (e.g., Angrist and Pischke, 2009, Chapter 5).

In the first three columns we show the results from estimating the model with a lagged dependent variable without country fixed effects; we shall label these estimates $\hat{\pi}^{N F E}$. From column 3 we observe that $\hat{\pi}_{1}^{N F E}=0.263$ (standard error $\left.=0.13\right)$ and $\hat{\pi}_{2}^{N F E}=-0.265$ (standard error $\left.=0.14\right)$. In comparison, we found in our fixed effects setting $\hat{\pi}_{1}^{F E}=0.320$ and $\hat{\pi}_{2}^{F E}=-0.165$ (standard error $=0.22$ ), see column 6 of Table 2. Accordingly, the principal baseline finding of an impact from temperature on growth appears fairly robust, with a point estimate somewhere between 0.26 and 0.32 .

\section{Table 3 about here}

Arguably, however, the Nickell bias is less important in "large T" samples. In particular, Barro (2015) argues that the so-called Nickell bias depends on the overall length of the sample period rather

\footnotetext{
${ }^{19}$ In a recent study Chenery and Hornbeck (2014) provide estimates for regions in Spain, which suggest convergence might have been very slow.
} 
than the number of periods. By implication, the Nickell bias from estimating eq. (9) with country fixed effects should be limited as we are considering a sample length of 800 years. Our second check, therefore, consists of including fixed effects in our lagged dependent variable specification. As seen from columns $4-7$, the results are very similar to the baseline results, consistent with the argument laid out in Barro (2015).

As a third and final check we employ the bias-corrected LSDV estimator suggested by Bruno (2005). The results are rather similar to our baseline estimates, albeit the two-step procedure (and associated loss of observations) makes for less precise estimates (see column 8). Overall, these checks show that our results are not sensitive to whether we allow for convergence or not.

\subsubsection{Time-varying determinants of population growth}

Another main worry regards the presence of time-varying determinants of population growth that are spuriously related to temperature. As observed above, the period in focus may well have experienced changes in productivity that were induced by geographic factors (such as institutional changes related to coastal orientation); if said geographic factors are correlated with temperature our estimates may be biased.

Accordingly, in Table 4 for allow for a rich set of geographic factors that are interacted with time fixed effects: longitude, latitude, percentage of land near water, irrigation potential, elevation, roughness, and agricultural land suitability (cf. equation 8). The estimates presented in Table 4 show that the baseline conclusion is robust to the mentioned geographical interactions. In fact, the effect of temperature is larger in magnitude and remains statistical significant at the 5 percent level when subjected to all the controls at once in column 7. The estimated coefficient on the lagged value of temperature is in some specifications negative and in others positive, however, it remains far from crossing conventional levels of statistical significance.

\section{Table 4 about here}

\subsubsection{Nonlinearities and temperature variability}

A third issue relates to nonlinearities; the influence of temperature may not be linear. To check, Table 5 augments the baseline specification by allowing for squared terms. As seen from columns 1-3, the point estimates on the linear terms do not change appreciably, albeit they do become somewhat less precisely estimated, while the point estimates on the square terms are statistically highly insignificant. 


\section{Table 5 about here}

Related to nonlinearities is the position that productivity may be more importantly influenced by climate variability. To check we computed a measure of temperature variability, which we subsequently included in our baseline specification, alongside mean temperature. ${ }^{20}$ The findings are reported in columns 4-6 of Table 5 . We find no effects of changes in climate variability as measured by the standard deviation of temperature (Temperature $S D$ ) and the lagged value of this variable (Temperature $S D$ lag), whereas the effect of temperature remains reassuringly stable in economical and statistical significance. The estimated coefficients suggest the effect of temperature on productivity growth is monotonic during the considered period.

\subsubsection{Sample Splits}

The countries in our sample varies greatly in size. As this may matter in terms of how resilient a country is to shocks (small countries may be more vulnerable) it seems worthwhile to examine whether "size matters" to the temperature/productivity nexus, for the period in question. Moreover, one may hypothesize that the influence of temperature on productivity may depend on the level of temperature itself. That is, perhaps the impact from changes in temperature differs if the country experienced high or low temperatures initially.

Columns 1-7 of Table 6 study the influence of small countries, as measured by population and area size. Columns 1 starts by excluding the small island countries: Iceland, Malta, and Cyprus. We find that the magnitude of the coefficient is reduced by about 15 percent compared to the baseline estimate, and since it is also somewhat less precisely estimated, the effect is only significant at the 17 percent level. This suggests that smaller nations might indeed be more sensitive to climate pertubations.

\section{Table 6 about here}

Yet, one may legitimately wonder if the conclusion of a positive impact-on average - from temperature on growth critically hinges on the presence of the island economies, or smaller nations in general. If this is the point of concern the above check is likely too extreme since there is no particular reason why the information conveyed by the three islands in our sample should be ignored altogether.

\footnotetext{
${ }^{20}$ Temperature variability is constructed by first computing the standard deviation of temperature across each $100-$ year period for each grid cell and then, second, deploing the previous explained algorithm for aggregating the data up to the country level.
} 
Hence, in columns 2-4 we provide alternative tests where a potential small-country issue is taken into account by weighted regression analysis. The weighted least square estimates - using, respectively, arable land, population size in $1000 \mathrm{CE}$, and population density $1000 \mathrm{CE}$ as weights - are positive and within the range of the baseline magnitude. Statistically the result are significant at least at the 10 percent level of significance.

Columns 5-7 investigate alternative potential heterogeneity in terms of population size by splitting the sample based on the median population in $1000 \mathrm{CE}$. Columns 5 and 6 demonstrate that the effect of temperature on productivity growth is larger for less populated countries, while column 7 demonstrate that the baseline result is unaffected in magnitude and statistical significance when allowing for different time trends in countries that initially were above or below median population density.

Finally, columns 8-10 propose a similar test based on initial median temperature. According to the reported estimates, there seems to be no heterogeneity of the effect of temperature on productivity growth in relation to whether we consider a relatively warm or cold climate.

Turning from sample pertubations in the "N-dimension" to the "T-dimension", one may wonder how the period that witnessed the onset of the "Black Plague" is affecting our estimates. As seen in Figure 1b, the population growth rate in 1400 is negative for most countries in the sample. This pattern is undoubtedly related to the spread of the Black Death in Europe during the period 1346-53, which may or may not be reacted to climate, as discussed in Section 2.

Table 7 therefore reports on the qualitative robustness of the results using a 200-year panel specification from $1100 \mathrm{CE}$ to $1700 \mathrm{CE}$, which, thus, excludes the post Black-Death century (i.e., the 15th century). It is reassuring to see that the baseline finding is if anything larger in magnitude (i.e., $\hat{\pi}_{1}=0.47$; standard error $=0.18$ ), while there remains no effect of the lagged value (i.e., $\hat{\pi}_{2}=-0.04$; standard error $=0.65)$. Hence, the onset of the Black plague only seems to mute the impact from temperature on growth, rather being key in explaining the presence of the "temperature gradient" itself.

Table 7 about here 


\section{Concluding remarks}

The present study provides estimates of the impact from temperature shocks on growth during the period from $1000 \mathrm{CE}-1800 \mathrm{CE}$ for 21 European and Asian countries. Our best estimates suggest that the shift from the Medieval Warm period to the Little Ice Age was contractionary in nature: lower temperatures instigated slower productivity growth. These results are consistent with contributions within economic history that view the Little Ice Age as having been detrimental to economic development.

A natural question to ponder is the extent to which the present results have bearing on what one should expect from global warming, in the years to come. Naturally, any such expectation will inevitably have to rely (in part, at least) on historical experiences. To be sure, in existing (so-called) Integrated Assessment Models the link between temperature and economic activity is parameterized on the basis of empirical estimations using historical data. In this regard our results might be a useful addition to the information set.

At the same time there are two important caveats worth bearing in mind. First, our analysis only comprises countries from Europe and Asia. In other words, our analysis carries no information on what might have transpired in arrid, or (sub-) tropical, areas around the world. These are the areas that often are expected to feel the consequences of global warming the most, and our analysis does not speak to the historical record of such regions. Second, our historical analysis only concerns the link between temperature and productivity; we are not able to separately control for precipitation due to data constraints. Insofar as the association between temperature and rainfall during the second millennium is expected to be different from that in the future, our reduced form result may not be a good guide to the impact of temperature changes going forward. 


\section{References}

[1] Acemoglu, D., Johnson, S., and Robinson, J., 2005. The rise of Europe: Atlantic trade, institutional change, and economic growth. American economic review, 546-579.

[2] Anderson, W., N. Johnson, and M. Koyama, 2015. Jewish Persecutions and Weather Shocks: 1100-1800, Economic Journal, (forthcoming).

[3] Acemoglu, D. and S. Johnson, 2007. Disease and Development: The Effect of Life Expectancy on Economic Growth. Journal of Political Economy 115, 925-985.

[4] Acemoglu, D., S. Johnson, and J. .Robinson, 2002. Reversal of Fortune: Geography and Institutions in the Making of the Modern World Income, The Quarterly Journal of Economics, 117(4), $1231-1294$.

[5] Acemoglu, D., S. Johnson, and J. .Robinson, 2005. The Rise of Europe: Atlantic Trade, Institutional Change, and Economic Growth. American Economic Review, 95(3), 546-579.

[6] Angrist, J.D., and J.S. Pischke, 2008. Mostly Harmless Econometrics: An Empiricist's Companion. Princeton University Press.

[7] Appelby, A.B., 1980. Epidemics and Famine in the Little Ice Age. Journal of Interdisciplinary History 10, 643-63.

[8] Arellano, M., and S. Bond, S., 1991. Some tests of specification for panel data: Monte Carlo evidence and an application to the employment equations. Review of Economic Studies, 58(1991), $277-297$.

[9] Ashraf, Q. and O. Galor, 2011. Dynamics and Stagnation in the Malthusian Epoch. American Economic Review, 101(August), 2003-2041

[10] Barro, R., 2015. Convergence and Modernization. Economic Journal, Economic Journal, 125(June), 911-942.

[11] Behringer, W., 1995. Weather, Hunger and Fear: Origins of the European Witch-Hunts in Climate, Society and Mentality. German History 13, p.1-27.

[12] Braudel., F., 1966. The Mediterranean and the Mediterranean World in the Age of Philip II, Vol I, 2.ed.Harper and Row Publishers. 
[13] Bruno, G.S.F., 2005. Approximating the bias of the LSDV estimator for dynamic unbalanced panel data models, Economics Letters, vol. 87, 361-366.

[14] Chaney E. and R. Hornbeck, 2014. Economic Dynamics in the Malthusian Era: Evidence from the 1609 Spanish Expulsion of the Moriscos. Forthcoming: Economic Journal.

[15] Clark, G., 2007. A Farewell to Alms. Princeton University Press.

[16] Dalgaard, C-J. and H. Strulik, 2014. Physiological Constraints and Comparative Economic Development. Discussion Papers Department of Economics University of Copenhagen, No. 14-21.

[17] Dalgaard C-J. and H. Strulik, 2015. The Physiological Foundations of the Wealth of Nations. Journal of Economic Growth 20, 37-73.

[18] Dell, M., B. F. Jones, and B. A. Olken, 2012. Temperature Shocks and Economic Growth: Evidence from the Last Half Century. American Economic Journal: Macroeconomics, 4(3), 66-95.

[19] Dell, M., B. F. Jones and B. A. Olken, 2009.. "Temperature and Income: Reconciling New CrossSectional and Panel Estimates. American Economic Review P\&P, 99(2), 198-204.

[20] Dell, M., B. F. Jones and B. A. Olken, 2014. What Do We Learn from the Weather? The New Climate-Economy Literature. Journal of Economic Literature, 52(3), 740-798.

[21] Deschenes, O., and M. Greenstone, 2007. The Economic Impacts of Climate Change: Evidence from Agricultural Output and Random Fluctuations in Weather. American Economic Review, $97(1), 354-385$.

[22] De Vries, J., 1980. Measuring the Impact of Climate on History: The Search for Appropriate Methodologies. Journal of Interdisciplinary History 10, p. 599-630

[23] De Vries, J., 2009. The economic crisis of the seventeenth century after fifty years. Journal of interdisciplinary history 40, 151-194.

[24] Diamond, J., 2005. Collapse: How Societies Choose to Fail or Succeed. Viking Press.

[25] Doepke, M., 2005. Child mortality and fertility decline: Does the Barro-Becker model fit the facts? Journal of population Economics 18, 337-366.

[26] Fagan, Brian. 2000. The Little Ice Age: how climate made history, 1300-1850. Basic Books: New York 
[27] Fogel, R., 1992. Second Thoughts on the European Escape from Hunger: Famines, Chronic Malnutrition, and Mortality Rates. In: Nutrition and Poverty, Osmani, S.R., ed., Oxford: Clarendon Press, pp. 243-286.

[28] Galloway, P. R., 1986. Long-term fluctuations in climate and population in the preindustrial era. Population and Development Review, 1-24.

[29] Galor, O., 2011. Unified Growth Theory. Princeton University Press.

[30] Heal, G. and J. Park, 2014. Feeling the Heat: Temperature, Physiology and the Wealth of Nations. Discussion Paper 2014-60. Cambridge, Mass.: Harvard Project on Climate Agreements.

[31] Iyigun, M., N. Nunn, N. 2015. Climate Change and Conflict: Evidence from 1400-1900, Preliminary Wp.

[32] Jia, R, 2014. Weather Shocks, Sweet Potatoes and Peasant Revolts in Historical China. Economic Journal 124, 92-118.

[33] Johnson, S., Larson, W., Papageorgiou, C., and Subramanian, A., 2013. Is newer better? Penn World Table revisions and their impact on growth estimates. Journal of Monetary Economics, $60(2), 255-274$.

[34] Kelly, M. and C. Ó Gráda, 2012. The Preventive Check in Medieval and Preindustrial England. Journal of Economic History 72, 1015-1035.

[35] Kelly, M. and C. Ó Gráda, 2014. The Waning of the little Ice Age: Climate Change in Early Modern Europe. Journal of Interdisciplinary History 44, 301-25

[36] Kiviet, J.F., 1995. On bias, inconsistency and effciency of various estimators in dynamic panel data models. Journal of Econometrics, 68.

[37] Lamb, H. H., 1965. The early medieval warm epoch and its sequel. Palaeogeography, Palaeoclimatology, Palaeoecology, 1, 13-37.

[38] Mann, M., 2002. Little Ice Age. In: Michael C MacCracken and Dr John S Perry (eds): "Encyclopedia of Global Environmental Change". John Wiley \& Sons, Ltd, Chichester

[39] McEvedy, C., and R. Jones. 1978. Atlas of World Population History. New York: Penguin Books. 
[40] McMichael, A.J, R.E. Woodruff and S. Hales, 2006. Climate Change and Human Health: Present and Future Risk. The Lancet 367, 11-17.

[41] Nickell, S., 1981. Biases in Dynamic ModelsWith Fixed Effects. Econometrica, 49, 1417-1426.

[42] NRC, 2010. Advancing the Science of Climate Change . National Research Council. The National Academies Press, Washington, DC, USA.

[43] Olmstead, A. L. and P. W. Rhode, 2011. Adapting North American wheat production to climatic challenges, 1839-2009. Proceedings of the National Academy of Sciences, 108(2), 480-485.

[44] Oster, E., 2004. Witchcraft, weather and economic growth in renaissance Europe', Journal of Economic Perspectives 18(1), 215-228.

[45] Parker, G., 2008. Crisis and Catastrophe: The Global Crisis of the 17th Century Reconsidered. American History Review 113, 1053-1079

[46] Schmida, B.V., U. Büntgenb, W. R. Easterdaya, C. Ginzlerb, L. Walløee, B. Bramantia, and N.C.. Stensetha, 2015. Climate-driven introduction of the Black Death and successive plague reintroductions into Europe. Proceedings of the National Academy of Sciences, www.pnas.org/cgi/doi/10.1073/pnas.1412887112.

[47] Waldinger M., (2014). The Economic Effects of Long-Term Climate Change: Evidence from the Little Ice Age, 1500-1750. Working paper. 


\section{Appendix: The Malthusian Model with Transitional Dynamics}

This appendix derives the empirical specification for the Malthusian model with transitional dynamics. The economy is closed and inhabited by overlapping generations who live for two periods. Time is discrete $t=0,1 . . \infty$. Households derive utility from own consumption and from the number of offspring, both of which are costly to attain. People are only economically active during their second period of life, where they work, supplying a unit of labor inelastically and decide on consumption and the number of offspring. During the first period of life, offspring live off their parents.

Assuming log utility and that people reproduce in proportion to their number, it follows that the number of inhabitants of the economy in generation $t+1$ is (for ease of exposition we drop the country index $i$ from the derivations):

$$
L_{t+1}=\nu_{t} Y_{t}
$$

$\nu_{t}$ in theory convolutes preference parameters, the unit cost of children, and influence from the (child) mortality environment. $Y_{t}$ is total income in generation $t . \nu_{t}$ is determined by temperature:

$$
\nu_{t}=\bar{\nu} e^{\rho T_{i t}}
$$

Production is given by

$$
Y_{t}=A_{t} L_{t}^{\alpha} X^{1-\alpha}
$$

where technology $A_{t}$ is determined by equation (5). Combining equations (10) and (12), the following law of motion for population size obtains:

$$
L_{t+1}=\nu_{t} A_{t} L_{t}^{\alpha} X^{1-\alpha}
$$

It is straight forward to show that, in the absence of temperature shocks, the model admits a unique globally stable steady state where population is constant. Taking logs and time differences of (13) results in:

$$
\ln L_{t+1}-\ln L_{t}=g+(\rho+\gamma+\beta) T_{t}-(\rho+\beta) T_{t-1}+\alpha\left(\ln L_{t}-\ln L_{t-1}\right) .
$$

This empirical specification which corresponds to this equation is (9) of Section 3. 
Table 1: Summary statistics

\begin{tabular}{lccccc}
\hline \hline & $(1)$ & $(2)$ & $(3)$ & $(4)$ & $(5)$ \\
& $\mathrm{N}$ & mean & sd & min & $\max$ \\
\hline Population growth & 168 & 0.192 & 0.275 & -0.693 & 0.788 \\
Log population & 168 & 7.789 & 2.123 & 2.303 & 12.71 \\
Temperature & 168 & 10.75 & 4.715 & 0.626 & 22.87 \\
Temperature lag & 168 & 10.80 & 4.705 & 0.626 & 22.87 \\
Temperature deviation & 168 & -0.280 & 0.282 & -1.092 & 0.611 \\
Temperature SD & 168 & 0.106 & 0.0537 & 0.0362 & 0.404 \\
Temperature SD lag & 168 & 0.112 & 0.0571 & 0.0362 & 0.404 \\
& & & & & \\
\# Countries & 21 & 21 & 21 & 21 & 21 \\
\hline
\end{tabular}

Notes: This table reports summary statistics for the main variables used in the analysis. We refer to the data appendix for further details. 


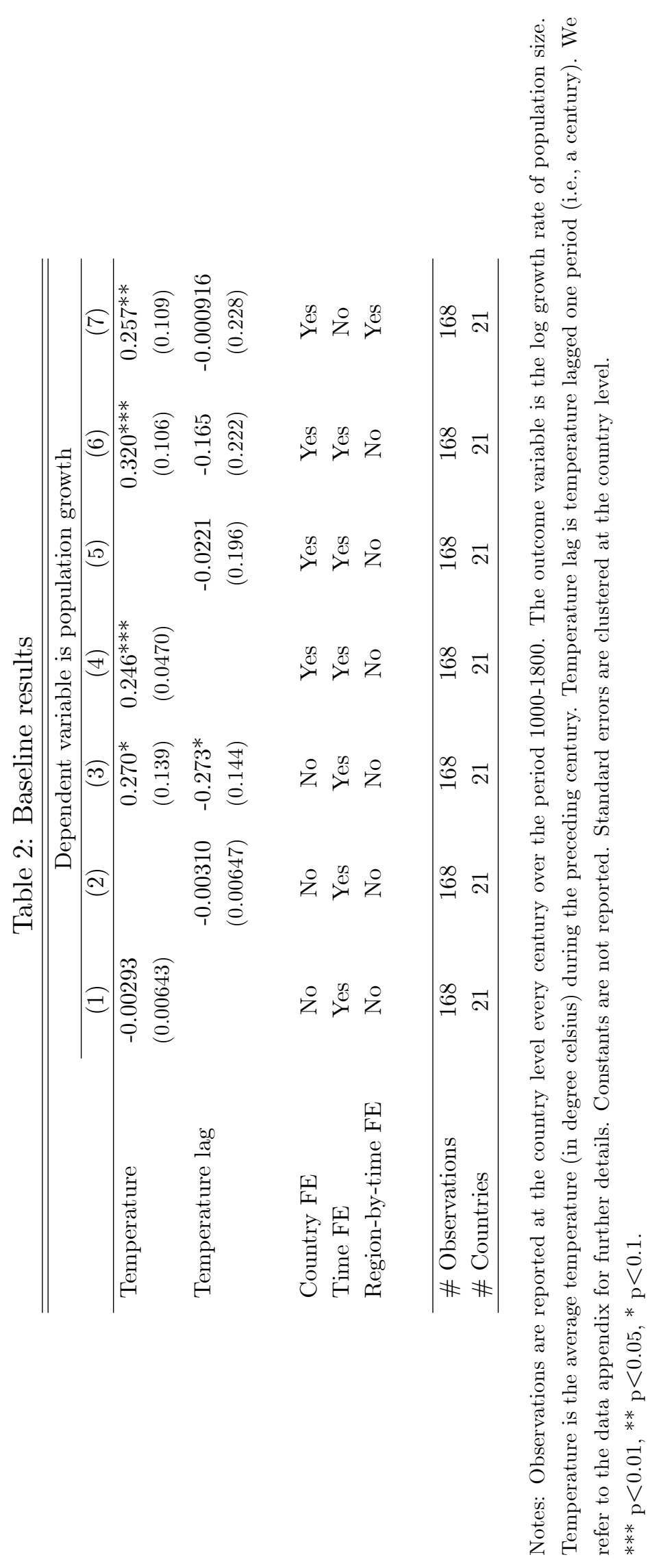




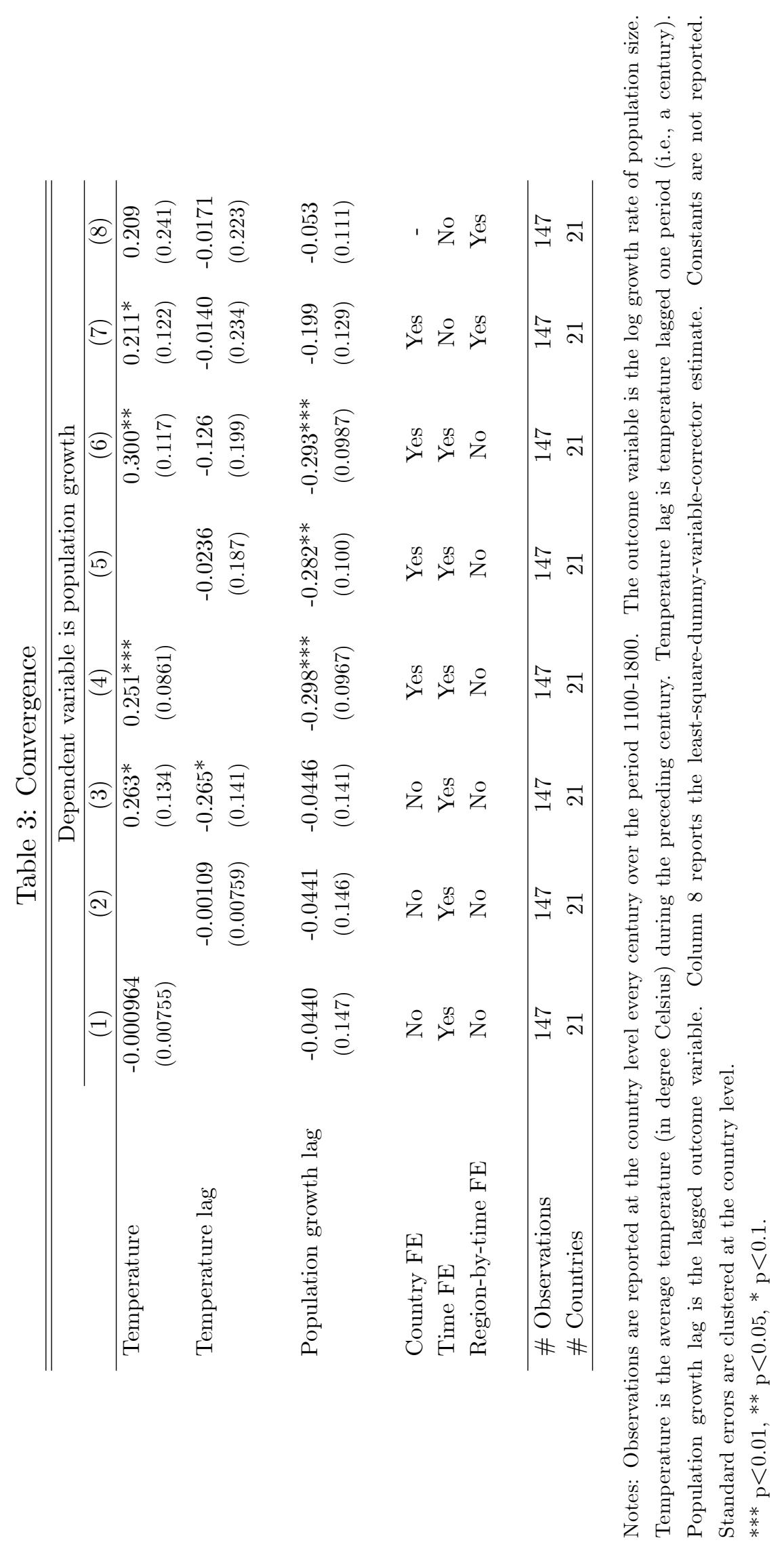




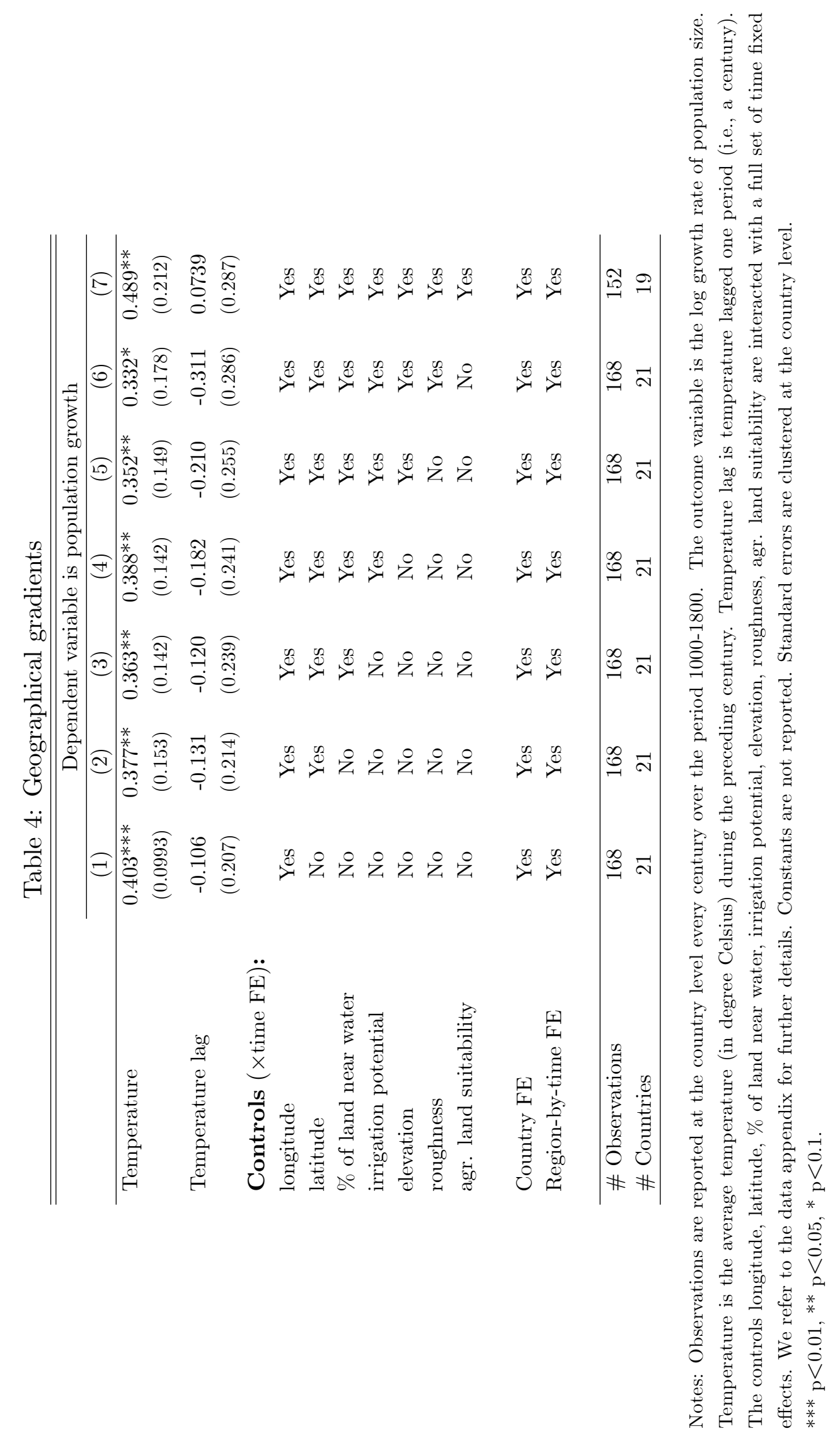


Table 5: Non-linear effects and climate volatility

\begin{tabular}{|c|c|c|c|c|c|c|}
\hline & \multicolumn{6}{|c|}{ Dependent variable is population growth } \\
\hline & \multicolumn{3}{|c|}{ Non-linear effects } & \multicolumn{3}{|c|}{ Climate volatility } \\
\hline & $(1)$ & $(2)$ & $(3)$ & $(4)$ & $(5)$ & $(6)$ \\
\hline Temperature & $\begin{array}{c}0.288^{* *} \\
(0.126)\end{array}$ & & $\begin{array}{l}0.205 \\
(0.152)\end{array}$ & $\begin{array}{l}0.247^{* *} \\
(0.0978)\end{array}$ & & $\begin{array}{c}0.221^{* * *} \\
(0.0749)\end{array}$ \\
\hline Temperature square & $\begin{array}{l}-0.0121 \\
(0.0119)\end{array}$ & & $\begin{array}{c}-0.00591 \\
(0.0112)\end{array}$ & & & \\
\hline Temperature lag & & $\begin{array}{c}0.147 \\
(0.184)\end{array}$ & $\begin{array}{l}0.0362 \\
(0.156)\end{array}$ & & $\begin{array}{l}0.0474 \\
(0.223)\end{array}$ & $\begin{array}{c}-0.0378 \\
(0.238)\end{array}$ \\
\hline Temperature lag square & & $\begin{array}{l}-0.0180 \\
(0.0113)\end{array}$ & $\begin{array}{l}-0.0127 \\
(0.0126)\end{array}$ & & & \\
\hline Temperature SD & & & & $\begin{array}{c}-0.0903 \\
(0.489)\end{array}$ & & $\begin{array}{c}-0.0879 \\
(0.491)\end{array}$ \\
\hline Temperature SD lag & & & & & $\begin{array}{l}-0.589 \\
(0.524)\end{array}$ & $\begin{array}{l}-0.475 \\
(0.516)\end{array}$ \\
\hline Country FE & Yes & Yes & Yes & Yes & Yes & Yes \\
\hline Region-by-time FE & Yes & Yes & Yes & Yes & Yes & Yes \\
\hline \# Observations & 168 & 168 & 168 & 168 & 168 & 168 \\
\hline \# Countries & 21 & 21 & 21 & 21 & 21 & 21 \\
\hline
\end{tabular}

Notes: Observations are reported at the country level every century over the period 1000-1800. The outcome variable is the $\log$ growth rate of population size. Temperature is the average temperature (in degree Celsius) during the preceding century. Temperature lag is temperature lagged one period (i.e., a century). 'Square' indicates that the given variable has been squared. Temperature SD is the standard deviation in temperature (in degree Celsius) during the preceding century. Temperature SD lag is the standard deviation of temperature lagged one period (i.e., a century). Constants are not reported. Standard errors are clustered at the country level.

*** $\mathrm{p}<0.01,{ }^{* *} \mathrm{p}<0.05,{ }^{*} \mathrm{p}<0.1$. 


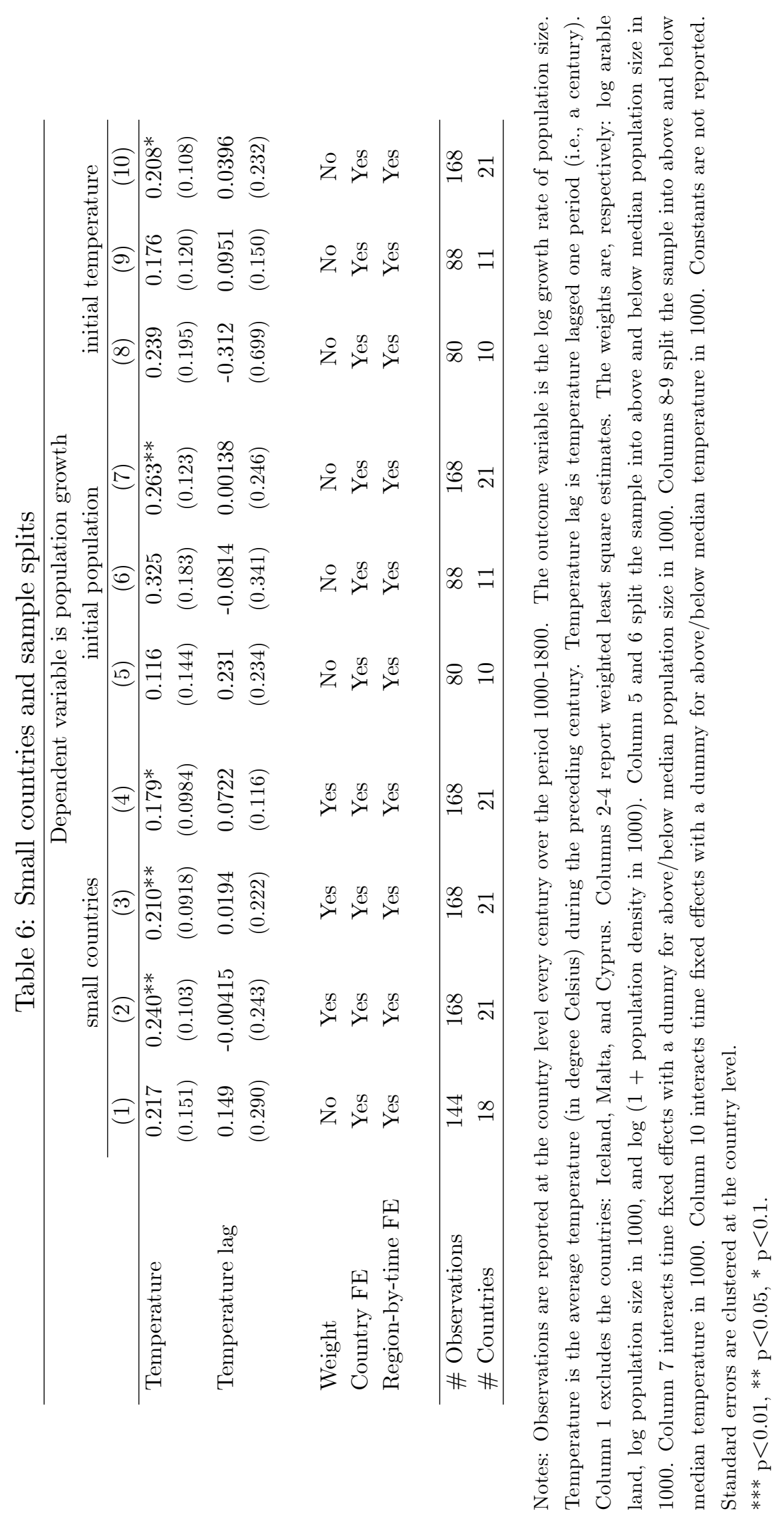




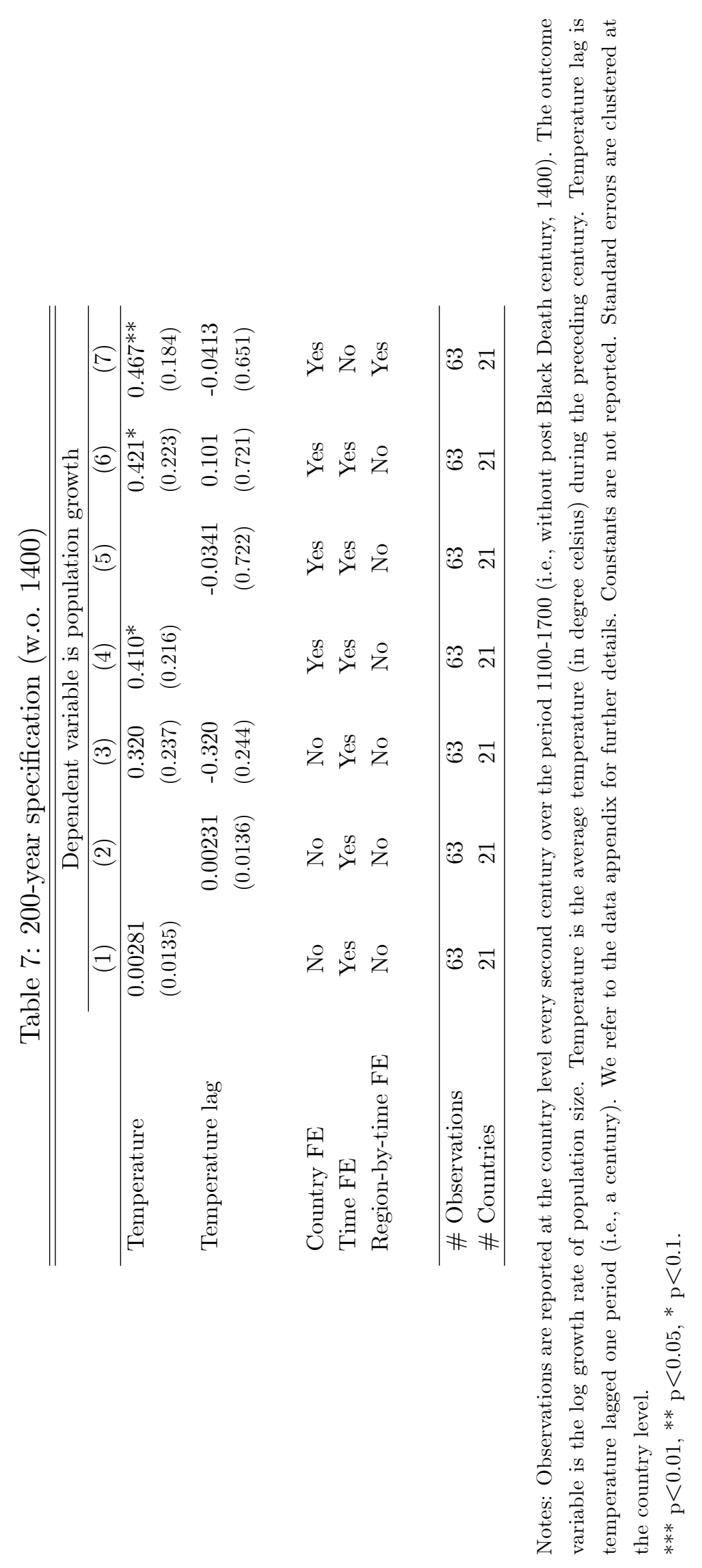

